\title{
A Gender Based Study Of Socio-Economic Impact Of Pension Systems
}

\author{
Muhammad Arshad \\ \& \\ Nasreen Aslam Shah \\ Department of Social Work \\ University of Karachi
}

\begin{abstract}
Respect for the elderly has always been a prevalent social norm in Pakistani society. Retired People in Pakistan have recently become visible due to changing social values. Karachi is the mega city of Sindh province. It is occupied with peculiar issues that need to be addressed at local, provincial and federal level. The aim of this study is to highlight the salient features on the life of the retired personnel in Pakistan. Retirement is often the first major transition faced by the older people. The objective of this study is to explore different aspects of retired people. Two hundred retired persons both male and female are interviewed by questionnaire method. The results were tabulated and analyzed by simple frequency and chi-square method. Results show that Pakistan is one of such countries where retired ageing people are becoming apparent. The old age affects males and females differently in terms of social adjustment at this stage of life. In old age, they are more likely to suffer from disabilities and multiple health problems. Family structure and living conditions influence the lives of elderly people. The present situation for elderly women is also quite poor. There is needed to make gender specific policies and programmes that can encourage and facilitate the elderly to have more involvement in activities of life through greater social and economic participation.

\section{حلفيصِ}

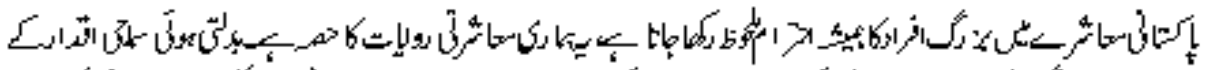

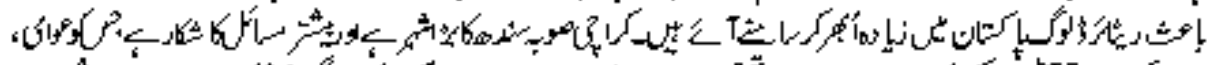

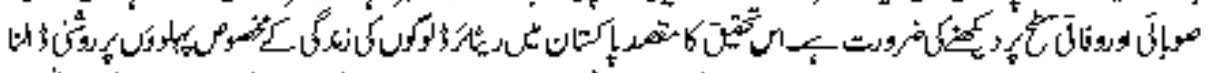

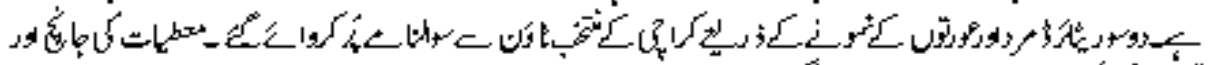
. U.

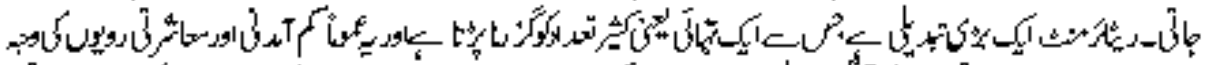

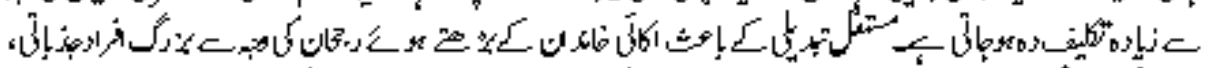
:

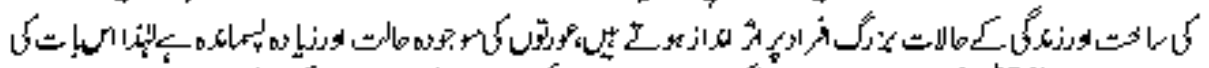

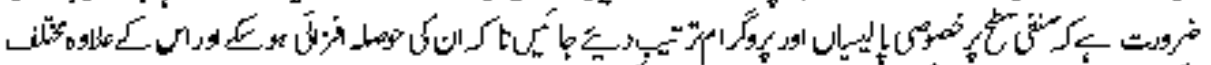
-
\end{abstract}


Key Words: Gender Based Study, Socio-Economic Impact, Pension System

Retirement is often the first major transition faced by the older people. It effects on physical and mental health differ from person to person. It depends on attitude towards old age and reason for retiring. About one third of the retirees, have difficulty in adjusting to certain aspects of retirement because of reduced income and altered social role and entitlements. The retired pensioners face socio-economic issues. Poverty is alleged as an obstacle to a secured old age. As such, the current pension system in Pakistan requires careful consideration and evaluation.

Due to rapid changes in society and the emergence of nuclear families and, the elderly are likely to be exposed to emotional, physical and financial insecurity in the years to come. Nuclear family, urbanization, modernization and social strains like poverty and economic insecurity are eroding the family support system leaving old people to take care of themselves (Zareen, 2014). They are thus seen as a burden on family's scant resources. Respect for the elderly has always been a prevalent social norm in Pakistani society (Khalid, 2005). Ageing has been defined as the total constellation of social, biological and psychological changes that occur in last stage of life (Richard, 1962).

Karachi is the mega city of Sindh province. It is also the business center of the country. It is occupied with peculiar issues that need to be addressed at local, provincial and federal level. Under government service rules, a decade ago the upper age limit for pension of government servants from scale 1-22 was 55 years. Later on it was extended to 58 years. Again the upper age for compulsory pension was further extended to 60 years.

Senior citizens in Pakistan have recently become visible due to changing social values. Until about two to three decades ago, their life span was around less than 60 years. They used to enjoy the love, affection and respect of their children and grand children. All their needs were met by their families. But now things are changing. With the passage of time, the problem of old age population has become severe (Cowgill, 1972). The aim of this study is to highlight the salient features on the life of the retired personnel in Pakistan.

In Pakistan, the elderly population is estimated to be 7.2 million and is steadily increasing about 10 percent of the total population. By the next decade it is expected to rise up to 15 percent of the whole population (Ronald, Manalastas, 2008).

Pakistan is also one of such countries where retired ageing people are becoming noticeably apparent. The number of elderly is growing. With increasing life expectancy and evidence of declining fertility, the future growth in the number of elderly in Pakistan is expected to be more conspicuous. It is estimated that the proportion of the elderly in the country will rise to more than 15 percent, 43 million in the year 2050. According to the UN, Pakistan's current population is estimated to be 185 Million. This population is definitely going to be an issue in 
the next decades if sincere steps are not taken to address this issue (Merckmanuals, Effects of Life Transitions on Older People http://www.merckmanuals. 2013).

There is, thus, a need for a strong commitment and a comprehensive policy that would cater to various needs of the pensioners in Karachi, Pakistan (Nasir, Z. M., 2003). The policy of changing the condition of poor from bad to worse and increasing the wealth of rich manifold should be changed. The government should not consider/claim that by increasing the salaries of govt. employees, being $5 \%$ of the total population, has solved the economic problems of the $95 \%$ poor citizens, among them approximately $70 \%$ are living below poverty line.

The article 25 of the 1973 constitution of Islamic Republic of Pakistan guarantees equality to all its citizens (GOP, 1973). The pensioners have to stay day long in queues in front of bank booths to receive their pension. There are no ramps on the pedestrian bridges for aged population. Older people are very important segment of the community including retirees, employees, business owners, careers, pensioners, frail aged and housebound, There are, however, a set of physical characteristics which are generally associated with ageing including deteriorating vision, deteriorating hearing, reduced mobility, weak physical strength and an increasing incidence of sickness. Several old pensioners including Mehmooda Begum were left at the Edhi Old home by her children. She became tired of eating porridge every day. Her children got married and turned their backs to her. All inhabitants at Edhi's Old Home have similar stories to share (Rana, 2008).

The old age affects males and females differently in terms of social adjustment at this stage of life. The marital status of the aged persons greatly influences their life style. Losing the spouse in old age brings a hard time in the passage of one's life. As the income position of the family increases the social adjustment of aged persons also increases. Better the economic position, better the social adjustment (Pak. J. Agri. Sci., 2008). Marital status is an important determinant in the wellbeing of the elderly as unbroken husband wife families constitute a multiple support system in terms of emotional, financial and social.

In old age, they are more likely to suffer from disabilities and multiple health problems. Low level of education and literacy are associated with low productivity and unemployment which increases the risk of different disease. There is need to encourage continuous training at work place and lifelong opportunities in the community lives. Cardiac disease is common among senior citizens. Cancer, though, has no specific cause is found mostly among these people. Mental health problems are also more prevalent as people grow older. 
Family structure and living conditions influence the lives of elderly people. The norms and values of our society exert pressure on us to show respect to the elder member of family and take care of them. It is basically a duty and responsibility of family head to provide suitable environment in which the elder member of the family spends their lives care free. Family structure and living arrangements of elderly people have changed substantially in the past few decades in underdeveloped countries (Ahmed, et.al. 2003).

The issue of changing family household structure in Pakistan has been documented by various studies. Many of the elderly people are not supported by their respective families to meet their basic needs and facing hardships in terms of respect, care, isolation, poor health, physical abuse (World Bank, 1987). Mostly elderly individuals do not get proper attention, (Karim, 1987). In extended or joint family set up due to large family size. On the other hand, the old age homes provide satisfactory services but these homes are unable to provide emotional and psychological satisfaction to the aged people. The breakdown of joint family system is creating problems for the elder members of the family (Thaver, et.al. 1998).

The loss of a spouse of elderly women is the most disorganizing life event they can ever withstand. Almost in all societies, probability of a man getting remarried when he loses his spouse is higher as compared to women. While 53 percent of women continue their lives as widowers, the percentage for men is 14 percent. Although percentage of living as a widower increases with age both for women and men, the ratio is higher for women.

In Pakistan elderly are active parts of the labor force. According to the labor force survey more than 70 percent of the male aged 60-64 years were reported as working population, but in age 65 and above, just about 45 percent were doing some work, the percentage among the female of these categories were less than 10 and about 4 percent respectively. Thus, with increase in age the work participation declined rapidly.

There is needed to make gender specific policies and programmes that can encourage and facilitate the elderly to have more involvement in activities of life through greater social and economic participation. The present situation for elderly women is also quite poor, except may be in the agricultural and the non-formal sector, but this position will change especially in the urban areas as more and more women are employed to develop skills and entrepreneurship.

The data on older women is hardly available regarding their exploitations. It is assumed that domestic violence is generally experienced by younger women. The older women's experiences can be put under the category of elder's abuse. The exploitation shows a lack of respect of retired people especially older women in particular and it is prevalent in many societies all over the world. 
Advice of the elder women in the house is very instrumental and cannot be ignored (Delgado, et.al. 1994). The primary function of the family institution is producing care to its family members. The rising rate of divorce, with social change, modern urban trends is affecting the family, and the trend toward smaller families is also affecting the future possibilities of home care for the aged. The future generations of old people may have few or no relatives to care for them. They may have weak family ties. The changing role of women also affects how the old are treated.

Historically, taking care of elderly has been the task of the daughter or daughter-in-law, who is full-time housewives. As the women continue to work outside their homes, they will be less able to care for aged parents. This situation has to be reviewed more carefully and it also demands more to take care of the family and elderly person together (Asian Population Studies Series, No.141). Radical changes have also taken place in the size, composition and living arrangements of families, ownership of property, and the focus of power. There is a weakening of the traditional and joint or extended family structures.

Establishing the levels of the labor force participation of Muslim women is a challenge to researchers because a high proportion of women's paid work, occurs in the informal economy. The levels of Muslim women's participation in the paid labor force are best explained by a particular economy's development strategy and consequent need for female labour. The Women's Pension Project is an activity of the Pension Rights Center committed to enhancing the economic security of older women.

No nation can rise to the height of glory unless its women contribute side by side with their male counterparts. It is a crime against humanity that our women are restricted within four walls of the houses as prisoners. There is no sanction anywhere for the deplorable condition in which our women have to live (Qutab, 2006).

In Pakistan, it is observed commonly, that decorum of individual can be measured through socio-economic status of the people of society, The women's access to property, education, employment etc. remains considerably lower compared to men's. The social and cultural context of Pakistani society is predominantly patriarchal, women have a low percentage of participation in society outside of the family.

Despite the improvement in Pakistan's literacy rate since its independence, the educational status of Pakistani women is among the lowest in the world. The literacy rate in urban women is more than five times the rate in rural women. The school dropout rate among girls is very high almost 50 percent.

The educational achievements of female students are higher as compared to male students at different levels of education. The Ministry of Women Development is a national focal 
Ministry for the advancement of women. It plays the role of advocate, planner and coordinator of women. It is responsible for formulation of policies and laws to meet the special needs of women ensuring that women interests and needs are adequately represented in public policy formulation by various organizations and agencies of government, promotion and undertaking of projects for development of women, matters relating to equality of opportunity in education, training, employment and facilities in health care and community development (Dyer, et.al. 2003).

The number of retired ageing people is increasing rapidly in Pakistan and there is no proper mechanism to address this issue. It is very much disturbing for ageing retired personnel who have no one to take care of them.

\section{Objectives of the Study}

The present study examined the socio-economic, health and domiciliary problems of the retired personnel in Karachi, which have been taken as the respondents of the study. The present study was conducted with the following general and specific objectives:

- To conduct a detailed analytical study on the conditions and problems of the retired personnel in Karachi.

- To identify the most important problems of the pensioners in Karachi.

- To investigate the needs and requirements of the pensioners and problems that disrupts their social, physical and economic

- To find out the socio-economic and domiciliary life of the retired personnel of Karachi.

- To find out the current health situation of the retired personnel.

- To know about the link between pensioners and departments concerned.

- To examine the socio-economic impact on ageing people due to delays in the payment of pension dues.

- To analyze the difficulties faced by the pensioners due to departmental proceedings.

- To identify the contribution of their families and governmental institutions to help them cope with diseases and disability.

- To investigate the role of government institutions in disbursement of pension to retired personnel.

\section{Research Methodology}

Research methodology refers to the broader principles of research underscored by philosophical rationales. Some social scientists have followed the scientific research methods, and prefer the quantitative methodology (Guthrie, 2010). The present research 
is extracted from an exploratory research. This research was determined to explore the "A Study of Socio-economic, Medical and Domiciliary Problems of the Pensioners (Retired Personnel) with Particular Reference to Karachi”.

Karachi city is the universe of the study. The city has six administrative districts and a total of eighteen towns under the six districts. Each town has union councils in its jurisdiction. There are around 178 union councils in the jurisdiction of city of Karachi. The systematic type of sampling is selected. It is a verification of the simple random sampling.

The sample collection has been done from the randomly selected five towns and one union council from each town. In the selection, one town from each district has been taken. The selected towns are: Baldia town, Union Council, Mahajir Camp, Gulshan-eIqbal town, Union Council, Karachi university and Jamshaid town, Tariq Road Malir town, Union Council, Kalaboard and North Nazimabad town,

A questionnaire was constructed for administrative "interview schedule" for collection of the data.The collection of the data constitutes the basic information out of which the conclusions have been drawn. In this study, the data collection involved three steps. The next stage after the collection of the data is its preparation for subsequent analysis. Once the data have been collected in a research study, the next step was analysis of data.

Computerized analysis was done, converted observation into numbers. This conversion process is called coding. In the present study, the chi-square test was applied to verify the relationship between two variables. Chi-Square is one of several statistical techniques used to test whether a set of sample results is simply a chance occurrence or, instead a reflection of something real going on in the population (Krejice, T. and Morgan, 1970). After the application of chi-square, the calculated results are compared with the tabulated degree of freedom. In the present study, chi-square test was applied to verify the relationship between two variables.

The data analysis was done by using computer. Presently, a number of statistical packages, such as SPSS, and others are available to analyze data. In this dissertation SPSS is used for data analysis. Following is the formula for calculating the degree of freedom. Df $=(\mathrm{r}-1)(\mathrm{c}-1)$

After finding the value of the table, the value of Chi-square for the particular level of significance was noted and compared with the calculated value of Chi-square for 0.05 level of significance. 


\section{Results:}

Table 1

Distribution of Respondents According to Gender

\begin{tabular}{|l|c|c|}
\hline Gender & Frequency & Percent \\
\hline Male & 172 & 86.0 \\
\hline Female & 28 & 14.0 \\
\hline Total & $\mathbf{2 0 0}$ & $\mathbf{1 0 0 . 0}$ \\
\hline
\end{tabular}

In this study $86 \%$ male and $14 \%$ female were interviewed in the research. Gender distribution of women in economic activities is strong indication of societal acceptance of female jobs and their share in decision making.

Table 2

Distribution of Respondents According to Marital Status

\begin{tabular}{|l|c|c|}
\hline Marital Status & Frequency & Percent \\
\hline Unmarried & 8 & 4.0 \\
\hline Married & 159 & 79.5 \\
\hline Widow/widower & 29 & 14.5 \\
\hline Divorce & 2 & 1.0 \\
\hline Separate & 2 & 1.0 \\
\hline Total & $\mathbf{2 0 0}$ & $\mathbf{1 0 0 . 0}$ \\
\hline
\end{tabular}

In this table, $79.5 \%$ majority of the respondents were married, and $14.5 \%$ were widows/widower, Majority of the respondents were married being $79.5 \%$, secondly $14.5 \%$ were widowed. The lowest numbers of respondents were divorced and separated. $4 \%$ of the respondents were unmarried.

Table 3

Distribution of Respondents According to Head of the Household

\begin{tabular}{|l|l|c|c|}
\hline $\begin{array}{l}\text { Head of the } \\
\text { Household }\end{array}$ & & Frequency & Percent \\
\hline \multirow{5}{*}{} & Self & 165 & 82.5 \\
\cline { 2 - 4 } & husband/ wife & 16 & 8.0 \\
\cline { 2 - 4 } & Son & 12 & 6.0 \\
\cline { 2 - 4 } & other (specify) & 3 & 1.5 \\
\cline { 2 - 4 } & Total & 196 & 98.0 \\
\cline { 2 - 4 } & No response & 4 & 2.0 \\
\hline & Total & $\mathbf{2 0 0}$ & $\mathbf{1 0 0 . 0}$ \\
\hline
\end{tabular}


Majority of the pensioners $(82.5 \%)$ enjoyed their elder hood as head of household. $6 \%$ sons were recorded themselves as family head in this study. $8 \%$ women led their families. It was noticed that elders are honored in our society. But discrimination against women was observed in the research.

Table 4

Distribution of Respondents According to Help and Support by Relatives

\begin{tabular}{|l|l|c|c|}
\hline \multicolumn{1}{|l|}{ Help and Support by Relatives } & Frequency & Percent \\
\hline \multirow{4}{*}{ Valid } & Always & 25 & 12.5 \\
\cline { 2 - 4 } & Sometime & 14 & 7.0 \\
\cline { 2 - 4 } & Never & 49 & 24.5 \\
\cline { 2 - 4 } & Total & 88 & 44.0 \\
\hline Missing & Not included & 112 & 56.0 \\
\hline Total & $\mathbf{2 0 0}$ & $\mathbf{1 0 0 . 0}$ \\
\hline
\end{tabular}

In the degree of financial help $44 \%$ respondents answered this question among them majority of the respondents were found clear on it, that no one provided them financial help permanently, whereas, $12.5 \%$ of all the respondents replied that the financial help is available for them on permanent bases.

Table 5

Distribution of Respondents According to Change in Life after Retirement

\begin{tabular}{|c|c|c|c|}
\hline \multicolumn{2}{|c|}{ If Changes in Life after Retirement } & Frequency & Percent \\
\hline \multicolumn{2}{|c|}{ siblings are not caring } & 17 & 8.5 \\
\hline \multicolumn{2}{|c|}{ no one caring in sickness } & 16 & 8.0 \\
\hline \multicolumn{2}{|c|}{ not allowing to travel with them } & 23 & 11.5 \\
\hline \multicolumn{2}{|l|}{ Other } & 17 & 8.5 \\
\hline \multicolumn{2}{|l|}{ Total } & 73 & 36.5 \\
\hline \multirow{3}{*}{ Missing } & NOT Include & 126 & 63.0 \\
\hline & System & 1 & .5 \\
\hline & Total & 127 & 63.5 \\
\hline \multicolumn{2}{|l|}{ Total } & 200 & 100.0 \\
\hline
\end{tabular}

In the above table in $8.5 \%$ respondents complained that their siblings did not take care of them, whereas, in $8.0 \%$ the respondents told that there was no one to take care of them, $8.5 \%$ had no specific reasons and $11.5 \%$, were not allowed to travel with their family members. 
Table 6

Distribution of Respondents According to Expenses on Illness

\begin{tabular}{|l|l|c|c|}
\hline \multicolumn{2}{|l|}{$\begin{array}{l}\text { Who Afford the Expenses of } \\
\text { Your Illness }\end{array}$} & Frequency & Percent \\
\hline \multirow{4}{*}{} & Others & 1 & .5 \\
\cline { 2 - 4 } & Self & 139 & 69.5 \\
\cline { 2 - 4 } & self, son & 16 & 8.0 \\
\cline { 2 - 4 } & self, wife & 1 & .5 \\
\cline { 2 - 4 } & Son & 43 & 21.5 \\
\cline { 2 - 4 } & Total & $\mathbf{2 0 0}$ & $\mathbf{1 0 0 . 0}$ \\
\hline
\end{tabular}

In the above table, $69.5 \%$ respondents replied that they afforded all expenses of illness by themselves, whereas, $21.5 \%$ answered that their sons were responsible to bear all expenses of their illness.

Table 7

Distribution of Respondents According to Care during Illness

\begin{tabular}{|l|c|c|}
\hline Who Takes Care You during Sickness? & Frequency & Percent \\
\hline Daughter & 3 & 1.5 \\
\hline daughter, wife & 1 & 0.5 \\
\hline Self & 55 & 27.5 \\
\hline self, son & 44 & 22.0 \\
\hline self, son, daughter & 5 & 2.5 \\
\hline self, wife & 4 & 2.0 \\
\hline self, son, son in law & 1 & 0.5 \\
\hline Son & 2 & 1.0 \\
\hline Son & 72 & 36.5 \\
\hline son daughter, wife & 5 & 2.5 \\
\hline Wife & 8 & 4 \\
\hline Total & $\mathbf{2 0 0}$ & $\mathbf{1 0 0 . 0}$ \\
\hline
\end{tabular}

In the above table, $36.5 \%$ respondents replied that their sons were responsible to take care of them during illness, whereas, $27.5 \%$ answered that they were taking care by themselves, as no one was available to meet this responsibility. 
Table 8

Distribution of Respondents According to Caring Grand Children

\begin{tabular}{|l|l|c|c|}
\hline \multicolumn{2}{|l|}{$\begin{array}{l}\text { Do You have to Take Care } \\
\text { of Grand Children? }\end{array}$} & Frequency & Percent \\
\hline \multirow{4}{*}{ Valid } & yes & 95 & 47.5 \\
\cline { 2 - 4 } & no & 62 & 31.0 \\
\cline { 2 - 4 } & sometime & 43 & 21.5 \\
\cline { 2 - 4 } & Total & $\mathbf{2 0 0}$ & $\mathbf{1 0 0 . 0}$ \\
\hline
\end{tabular}

The above table states that the respondents' taking care of their grand children, $47.5 \%$ had to take care of their grand children, $31.0 \%$ were not required to take care of their grand children, while $21.5 \%$ took care of their grand children some time.

The study revealed that every woman whose husband died, has experienced a painful period of bereavement, often accompanied by severe loneliness, obsessive thoughts of the deceased, restlessness, insomnia, somatic complaints, and even hallucinations of the deceased, and poor mental well-being.

\section{Discussion}

Access to health and basic necessities of life are basic human rights; and these are duly accepted in article 25(1) and others in 1973 Constitution of the Islamic Republic of Pakistan, articles 38, 39 and few more in the section of basic rights of the citizens. Until 2011 , health was the responsibility of the federal government. After the $18^{\text {th }}$ amendment, it has become a provincial subject. Citizens' health is based on government health policies. International monetary policies, influence national policies and the gap between the rich and the poor in society are directly related to the health of people. The have-nots are increasing rapidly day by day in Pakistan due to joblessness and unemployment. Health is only basic criteria for hiring a person on a particular job for a particular duration of 25 years or till the age of 60 years. Some who are good in health are re-employed.

In government's health systems, the lack of good governance and poor community involvement is reflecting government's performance in this sector. Health and Population Welfare Programmes in Sindh are suffering due to institutional weaknesses. The governance's weaknesses of the health department have become reasons for health institutions' failure in providing health services to the elderly. Health care sector continues to have glaring weaknesses all over Pakistan. NGOs come forward and fill this gap for providing health services. NGOs and community working together may resolve the situation. 
Around 6000-9000 persons per acre in Karachi city are causing skin diseases like scabies, ARI, GIT etc. and psychosomatic illnesses due to over population and high densification. In slum's environment diarrheal and psychosomatic illness and other related issues are unavoidable. All this is aggravating the situation among low income people living in low income areas of the city. Low wages and, consequently, very low rate of pension in many public and private departments do not help majority of the pensioners to live peaceful lives during the job and even after retirement. Ignorance among the pensioners of their rights and even annual increase sometimes deprives them of many of their rights.

\section{Conclusions}

The present study intended to examine the Socio-economic, Medical and Domiciliary Problems of the Pensioners (Retired Personnel) with particular reference to Karachi. This study has arrived at the following conclusions:

1. It was found that most of the retired pensioners were living in large-size families; their family members on account of socio-economic activities did not give them proper attention.

2. It was noticed that a large section of pensioners were in poor economic conditions. Therefore, they needed economic support of their family, government institutions and NGOs working for improvement of the ageing people.

3. It was observed that senior citizens needed respect, care and company but at the same time they also had to learn to be patient and tolerant with those looking after them. Furthermore, they were not fully satisfied with the attention given to them by their family members.

4. It emerged that crisis of older people living in rich families was that of ignorance or lack of attention by the young family members. This was due to ignoring our religious and cultural traditions and adoption of western culture, where senior citizens are not given importance; they feel themselves useless creating in them disappointment and frustration.

5. It was noticed that problem of middle class or poor families were that of resources. Due to limited family income, it was very difficult for them to satisfy the needs of their elders. Also, this is the age when one mostly suffers from various diseases, and inability to work.

6. It was also discovered that the size of these families was usually bigger but their income was mostly lower. Here elders, though not ignored but economic problem disturbed both the family members and the elders.

7. It was revealed that welfare schemes and social uplift plans for the retired pensioners were virtually non-existent. Only support they could get was from their own life-long savings or the earnings of their children, both being insufficient. Hence, economic constraints define the problem of old age. Food, health and love needs of the elderly people were rarely satisfied fully. 


\section{References}

Ahmed, S.M. Adams, A.M. Chowdhury. M, Bhuiya, A. (2003). Changing Health Seeking Behavior in Matlab: Do Development Interventions Matter?, Health Policy Plan; vol. 18, pp. 306-315.

Concepcion, M.B. (1995). The Graying of Asia: Demographic dimensions. Asia Population Studies, Series No.141, Chapter 2. www.un.org/depts/escap/pop/ apss141/chap2.htm.

Cowgill, D. A. (1972). Theory of Ageing in Cross-Cultural Perspective, In D. Cowgill \& L. Holmes (eds.) Ageing and Modernization, New York.

Delgado E, Sorenson SC, Van der Stuyft P. (1994). Health Seeking Behaviour and Self Assessment for Common Childhood Symptoms in Rural Guatemala, Inn SocBelg Med Trop 74, pp. 161-168.

Dyer, C., Connolly, M.T., McFeeley, P. (2003). The Clinical and Medical Forensics of Elder Abuse and Neglect, In: Bonnie R, Wallace R, National Research Council, eds. Elder mistreatment: abuse, neglect, and exploitation in an aging America. Washington, DC, The National Academies Press, 2003, pp, 339-375.

Effects of Life Transitions on Older People http://www.merckmanuals.com/home/older_ peoples_health_issues/social_issues_affecting_older_people/effects_of_life_transi tions_on_older_people.html (seen March 24, 1014)

GOP (1973). Constitution of Pakistan, National Assembly Secretariat of Pakistan, (Islamabad).

Gulzar, F., Zafa R, M. I., Ahmad, Ashfaq \& Ali, Tanvir (2008). Socio-Economic Problems of Senior Citizens and their Adjustment in Punjab, Pakistan, Pak. J. Agri. Sci., vol. 45(1).

Guthrie, G. (2010). Basic Research Methods: An Entry to Social Science Research, London: Sage.

Karim, M. S. (1987). Socio-Economic, Demographic and Health Situation in District, Karachi: Aga Khan University.

Khalid, M. (2005). Social Work: Theory and Practice, Karachi: Kifayat Academy. 
Krejice, T. \& Morgan (1970). Research Methods, London: Sage.

Nasir, Z. M. (2003). Economically Active Population, Employment, and Unemployment in Population of Pakistan: An analysis of 1998 Population and Housing Census. Islamabad: Pakistan Institute of Development Economics, pp. 285-311.

Qutab Institutional (2006). Elder Abuse in India: A Country Report for World Health Organization Shubha Soneja Help Age India C-14, Area New Delhi 10016Qutab Institutional.

Rana, R. (2008). A Study on Status of Senior Citizen of Kathmandu Metropolitan City, Kathmandu, Khatmandu Nepal: SIRF Secretariats, Netherlands: Development Organization Bakhundol, Lalitp.

Richard, (1962). Ageing and Personality, New York: John Wiley and Sons Inc.

Ronald, Manalastas, (2008). What is the Most Important Problem that Senior Citizens Face Today, http://www.relating360.com/index.php/what-is-the-most-importantproblem-that-senior-citizens-face-today-2-34236/(seen May 25, 2014).

Thaver, I, Harpham, T, McPake, B, Garner, P. (1998). Private in the Slums of Karachi: What Quality of Care Do they Offer?, SocSciMed, Vol. 46, pp. 1441-1449.

World Bank (1987). Pakistan Poverty Assessment, Poverty in Pakistan: Vulnerabilities, Social Gaps, and Rural Dynamics. Poverty Reduction, Islamabad: World Bank.

Zareen, S. (2014) Joint Family System, Nawa e Waqat (Karachi) (May 24, 2014).

Muhammad Arshad is Lecturer in the Department of Social Work, University of Karachi.

Dr. Nasreen Aslam Shah is Meritorious Professor, Department of Social Work and Director, Centre of Excellence for Women's Studies, University of Karachi. 